\title{
Study on the Supervision System of Commercial Insurance in China
}

\author{
Dan Cui \\ Business administration school, Dalian Vocational \& technical College, Dalian Liaoning 116035, \\ China
}

1471378931@qq.com

\begin{abstract}
Keywords: Commercial Insurance, Regulatory System, Practical Experience, Strategy.
\end{abstract}
\begin{abstract}
The supervision of commercial insurance is an important part of financial supervision. For a long time, there are many studies on the banking and securities regulatory system in China, and the research system is more perfect. However, there is little research on the issues related to the regulation of commercial insurance. This is not consistent with the systematic importance of the insurance institutions in the financial system, and is not consistent with the increasing economic status of the insurance industry in the national economy. Therefore, the actual situation of domestic insurance supervision is studied. The experience of insurance supervision in developed countries is used for reference. The basic concept and necessity of commercial insurance regulation are explained. The basis and significance of the regulatory system of commercial insurance are analyzed. Finally, the path of perfecting China's commercial insurance supervision system is proposed.
\end{abstract}

\section{Introduction}

Commercial insurance plays an unparalleled role in maintaining social stability, financing demand and promoting economic development. Since the beginning of the new century, China's insurance industry has increased in the national economy [1]. The average annual growth rate is significantly higher than the GDP growth rate in the same period, and the premium scale is in the forefront of the world. In the financial industry, the insurance market is the first to open to the outside world. The scale of the commercial insurance market has been expanding. The main body of the commercial insurance market has been increasing, and it has put forward higher requirements for the establishment of a perfect system of the legal system of insurance supervision. The supervision of commercial insurance is an important part of financial supervision. In the world, it is a financial supervision "three carriages" which are tied up with banking supervision and securities regulation. In essence, market economy is a rule of law economy, and also a system economy. Effective insurance supervision should be based on effective supervision system and complete and feasible regulatory law [2].

The practice of market economy since the reform of China has proved that the legal system of socialism with Chinese characteristics is perfect [3]. On the one hand, the regulatory system and supervision experience of the developed countries in Europe and the United States should be used for reference. On the other hand, China's national conditions are closely integrated and studied. Both of them are indispensable to each other. In this paper, the current situation of China's commercial insurance regulation is clarifying to a certain extent. The legal, institutionalized and internationalized level of China's commercial insurance regulation has been explored. The excellent level of governance can promote the benign development of the industry. The basic concept of commercial insurance supervision and the structure principle of the legal system system are discussed. At present, the problems and defects in the practice of commercial insurance supervision are analyzed. Based on the experience of the insurance supervision system and the legal system of western developed countries, the improvement measures are put forward in accordance with the development level and potential of China's commercial insurance [4]. It provides theoretical and practical methods for further improvement of China's commercial insurance regulatory system. 


\section{Basic theory of commercial insurance regulation}

The first known insurance law in the world is the British insurance act in early fifteenth Century, and the insurance act was set up. A special insurance arbitration tribunal was established to solve the possible disputes in marine insurance in time. Generally speaking, there are two main components of insurance regulation. One is the law of insurance supervision, and the other is the insurance regulatory agency. In the modern sense, the insurance regulation law first appeared in the rapid development of capitalism in the United States [5]. In 1810, the state of Pennsylvania passed a law that forbids foreign state insurance companies to start insurance operations in the state. Some states have also promulgated this kind of law, which is the earliest modern law of insurance supervision. The landmark event in the beginning of insurance regulation took place in 1851. The New Hampshire State Insurance Commission was announced in this year. In the modern sense, the insurance supervision department was the New York state insurance supervision committee, which was set up in 1859. Although there is no uniform definition of the concept of commercial insurance regulation, the connotation of different definitions is generally consistent. From the perspective of the subject of supervision, it can be divided into two types: general insurance supervision and narrow sense insurance supervision. Generally speaking, insurance supervision mainly refers to the supervision and management of the entire insurance industry by regulatory agencies, industry regulatory bodies, industry internal audit institutions and all sectors of society. From a narrow sense, insurance supervision refers to the specific supervision and management of specific insurance companies according to specific laws or administrative authorization [6]. The insurance supervision discussed in this paper mainly refers to the narrow sense of commercial insurance supervision, that is, the special insurance regulatory agencies within the government are responsible for and targeted commercial insurance supervision.

The state intervention of the insurance industry is mainly manifested by two distinct regulatory paths. One is the theory of passive supervision, and the other is the theory of active supervision. The theory of passive regulation encourages market competition [7]. The theory suggests that the government should take the strategy of letting market competition instead of intervening, and build effective market through orderly competition, so as to promote the development of industry. The active regulatory theory is more focused on strict supervision, which requires full process, omni bearing and multi field supervision and management for market behavior, insurance market main body solvency, corporate governance and information disclosure of insurance companies. Insurance supervision should be based on a complete legal basis. The law of insurance supervision is the general term of the laws and regulations involved in the supervision and management of commercial insurance by the state insurance regulatory agency. At present, there are two kinds of laws on commercial insurance in the world, including insurance supervision law and insurance contract law. The laws and regulations of insurance supervision are the basis for the state insurance regulatory authorities to exercise regulatory power, perform regulatory responsibilities and carry out effective supervision [8]. At the same time, it is also the norm that the commercial insurance institutions must follow in the daily operation. The benefit value of the insurance supervision law is reflected in the needs of the development of the insurance industry in the country or region, which provides efficiency guarantee for the development of commercial insurance.

\section{The main problems of China's commercial insurance regulation}

For a long time, China has insisted on strict supervision and regulation, especially through the supervision of market behavior, in order to ensure the steady development of the insurance industry. On the one hand, strict regulatory methods can protect the legitimate rights and interests of consumers, achieve an orderly management of the insurance market, and promote the healthy, sustained and steady development of the insurance industry. On the other hand, the strict supervision mode also inhibits the innovation of insurance products and modes, which is not conducive to the market playing a fundamental role in the allocation of resources, to a certain extent, hinder the development of the industry. At present, the domestic insurance regulatory thinking has not yet had the corresponding 
strategic foresight. It manifests itself in the diversification and multiplicity of regulatory objectives and targets, which are often difficult to reconcile. Insurance regulators play the dual role of regulatory body and industry leadership. At present, the most important legal basis for domestic insurance supervision is the "Insurance Law of the People's Republic of China." However, the relevant content of the supervision is often only a general description, and has a strong macro level. It lacks the operational rules of implementation. In the specific regulatory practice, these departments can only refer to the special laws and regulations promulgated by the State Council and all kinds of departments, industry rules and regulations and normative documents formulated by the China Insurance Regulatory Commission (CIRC). Although the Insurance Regulatory Commission has issued a lot of insurance regulatory system and normative documents, it basically covers all the contents of insurance supervision, and the legal level of these regulations and normative documents is relatively low [9]. It has limited legal effect, which indirectly leads to the uncertainty of the regulatory effectiveness of the insurance regulatory authorities in the process of supervision. To a certain extent, it weakens the authority and effectiveness of insurance regulation.

The market economy is essentially a rule of law economy, and the effective insurance supervision should be based on the complete regulatory mechanism and the supervision law. However, there are still some problems that need to be improved in the domestic legislation system of insurance supervision, which are shown in the following aspects. These laws do not constitute an organic whole. Some of the laws and regulations also appear in the content of the contradictions. On the other hand, some of the new problems in the development of the industry often become vacuum zones, and all laws and regulations have not been involved. From this point of view, the domestic legislation mechanism of insurance supervision needs further improvement and development. The commercial insurance regulation itself is a complex systematic project. However, the various departmental regulations formulated by the CIRC are often specific to a particular aspect. It is difficult to form a unified and effective legal system. The rules themselves are complex and lack of coordination and unity. There will be conflicts between the different regulations set up by the CIRC. The regulations and systems of other departments are lower at the legislative level. The regulations on some problems are relatively vague. The operability is not very strong, which is not conducive to the legal operation of insurance companies and supervision by law. The business insurance in China started late. The scale of premium, the number of employees and the scale of the use of funds are among the top in the world. However, barbarous growth was once a popular phenomenon in the industry. Some companies are digging up executives and marketing teams for business development, and laying out branches in various places. Due to quantitative restrictions, regulatory power is weak. Regulation is difficult to cover all the grassroots insurance organizations. The CIRC not only bears the responsibility of standardizing the insurance market and the insurance company, but also bears the responsibility of promoting the development of the industry. At this stage, a number of financial holding companies, such as CITIC Group, Guangda group and Ping An insurance group, have also appeared in China. The current financial division supervision mode in China faces the new form of the financial holding company. It is difficult to avoid the blind area of supervision. There is a profound contradiction between the mixed operation of the financial and insurance industry and the division supervision.

\section{Enlightenment of insurance supervision system in developed countries}

With the continuous development of the commercial insurance and the financial industry, the supervision system and the environment of the rule of law must be constantly improved. Since 1950s, the major developed countries, such as Britain, the United States, Germany and Japan, have changed the past patterns of overregulation. It is a trend of assimilation and integration to learn from each other in the aspects of supervision and legislation. For example, the UK has gradually realized the loose supervision of commercial insurance through the financial regulatory service. The United States has established the management form of the financial holding company by abolishing the restrictions on the division of business. In summary, the main western developed countries have the following regulatory experience for reference. 
First, the developed countries have a relatively complete legal system for commercial insurance regulation. As the first country to appear in the modern insurance industry, the British government has issued a series of insurance legal systems and related insurance regulations. These laws and regulations constitute the legal system of insurance regulation in the UK. Although the United States federal government has not formulated a unified insurance law, the states have formulated an insurance regulation law suitable for the conditions of the states according to their own actual conditions. Under the unified coordination and organization of the national insurance supervision Association (NAIC), the regulatory laws of the states have become more and more converging in content. Through the two fundamental laws of the insurance regulation law and the insurance contract law, the legal framework of the German commercial insurance regulatory system has been set up.

Second, the regulatory system of commercial insurance has been constantly improved. The process of the continuous development of commercial insurance in developed countries, such as Britain, the United States, Germany and Japan, is also the process of continuous improvement of its regulatory system. After several generations of supervisors' efforts, the system of precise, complete and effective commercial insurance supervision has been gradually formed. For example, the UK has formed a commercial insurance regulatory system that combines government regulation with industry selfregulation formed by the Ministry of Finance, the Financial Services Bureau and the LRA Board of Directors. The United States has developed a two-line parallel commercial insurance regulatory system consisting of the Federal Insurance Regulatory Office, the State Insurance Regulatory Authority, the National Association of Insurance Inspectors and other non-affiliated federal and state regulatory agencies. Japan and Germany are gradually derived from the "double peak" regulatory model. Japan is jointly supervised by the Ministry of Finance and the Finance Ministry in the insurance industry. In Germany, the Federal Financial Supervisory Authority and the Pension Supervisory Authority are responsible for regulating the insurance industry. The common point of the above-mentioned countries in the insurance regulatory system is to establish or lead the establishment of an insurance regulatory agency by the government. A complete and effective commercial insurance regulatory system, which is consistent with the political and economic system and the degree of development in the country, has been explored.

Third, the developed countries pay more attention to the role of the self-discipline organization of the industry. Insurance supervision cannot be separated from the self-discipline cooperation of the insurance industry association. The insurance industry association, which has relatively detached status and high authority, plays an irreplaceable role in the supervision of the government. The western developed countries, especially the British and American insurance industry associations, have exercised part of the regulatory function on the one hand. On the other hand, on behalf of insurance companies, they give opinions to government regulatory authorities on insurance regulatory laws and regulatory implementation rules.

\section{Suggestions on improving the regulatory system of commercial insurance in China}

\subsection{Perfecting the legal framework of commercial insurance supervision}

The main content of the legalization of insurance supervision is the top-level design for the supervision and management of insurance regulatory organs, the establishment of power list, the straightening up of supervision procedures, and the identification of regulatory responsibilities. The legal direction of China's commercial insurance supervision should cover the whole process of the insurance supervision legislation, the insurance supervision and the law enforcement and the judicature. The whole process of setting up the legal system from the macro insurance supervision to the specific legal provisions has been formulated. The legal system of insurance supervision is not only to regulate the main body of the commercial insurance market scientifically, but also to restrict the insurance regulatory authorities. The establishment of the legal system is to serve the economic development. A country's supporting legal system is the refraction and projection of its economic development. The implementation of the insurance regulatory system must be based on law, and constantly strengthening the construction of laws and regulations is the only way to improve and perfect insurance supervision. The scientific and effective insurance contract law and the insurance 
supervision law are formulated respectively. China's current contract law and supervision law are all unified in the insurance law of the People's Republic of China, which leads to the relatively low operability and enforceability of our insurance law. It is difficult to effectively supervise the development of the insurance industry. It is suggested that the legislature of NPC should organize and formulate a scientific and effective "Insurance Contract Law" and "Insurance Supervision Law" according to the needs of the development of the times. The "Insurance Contract Law" belongs to the scope of civil contract, which focuses on adjusting the parties and the relationship between the insurance contract. The law of insurance supervision belongs to the category of public law. Its adjustment object is the insurance regulatory agency and the main body of the insurance market. The separate formulation of the contract law and the supervision law is conducive to refining the contents of insurance supervision and clarifying the positioning and nature of insurance supervision.

\subsection{Establishing efficient commercial insurance regulatory agencies}

The reform of the regulatory agency should be taken as the starting point to upgrade the supervision efficiency, and upgrade the supervision concept, mode and means of the renewal and renewal of insurance supervision. The overall reform of the regulatory body is essentially the upgrading of the regulatory system. It involves the re-determination of regulatory objectives, the improvement of regulatory concepts, the adjustment of regulatory approaches, the content of work and the transformation of working methods. Regulatory reform should be based on improving the effectiveness of regulatory actions. Laws, regulations and regulatory policies are important carriers of the regulatory concept of regulatory agencies. The reform of the regulatory agency and the existing regulations, such as laws and regulations, need to be revised and perfected. It is not only to meet the needs of new changes in the insurance market, but also in line with the new trend of international insurance regulation. The overall reform of the regulatory agency can set medium-term goals and long-term goals. The medium-term objective is the target that regulators will achieve within a certain period of time, so as to evaluate the progress of the reform and the actual results of the reform. Corresponding to the medium-term goal, the long-term goal reflects the regulatory guiding ideology of regulatory reform. Specifically, it includes a complete internal risk control mechanism that complies with clear regulatory objectives and regulatory behaviors, and a risk management and control system that is consistent with international regulatory standards. Scientific insurance supervision is a powerful guarantee to lead the development of insurance industry, guard against risks and protect the interests of insurance consumers.

\section{Conclusion}

China has gradually established a relatively perfect regulatory system for commercial insurance. However, because of historical and practical reasons, there is a gap compared with the developed countries. With the globalization of the insurance market, the scale of domestic commercial insurance market has developed rapidly. The difficulty and challenge of insurance supervision are gradually increasing. Although the global financial crisis has passed, the legal system of insurance supervision in China should be further perfected to reform the insurance regulatory system, so as to promote the sustained, steady and healthy development of the insurance industry. The development of China's insurance regulatory system and its existing problems are analyzed. By drawing on the advanced experience of the insurance supervision system in the developed countries, especially the insurance supervision law, the suggestions for improving China's insurance supervision system have been proposed.

\section{References}

[1] Zhang, D., Cai, J., Dickinson, D. G., \& Kutan, A. M. (2016). Non-performing loans, moral hazard and regulation of the Chinese commercial banking system. Journal of Banking \& Finance, 63, 48-60.

[2] Barth, M. E., Gomez-Biscarri, J., Kasznik, R., \& López-Espinosa, G. (2017). Bank earnings and regulatory capital management using available for sale securities. Review of Accounting Studies, 22(4), 1761-1792. 
[3] Alessandrini, P., Fratianni, M., Papi, L., \& Zazzaro, A. (2016). Banks, regions and development after the crisis and under the new regulatory system. Credit and Capital Markets-Kredit und Kapital, 49(4), 535-561.

[4] Wen, S., Ma, J., Pan, Y., Qi, Y., \& Xiong, R. (2017). The Impact of Business Scale of "Shadow Banking” on Credit Risk of Commercial Banks--Take Ten Domestic Listed Commercial Banks as Examples. International Journal of Economics and Finance, 9(5), 94.

[5] Calomiris, C. W., \& Carlson, M. A. (2017). Rediscovering Macro-Prudential Regulation: The National Banking Era from the Perspective of 2015.

[6] Moutsianas, K. A., \& Kosmidou, K. (2016). Bank earnings volatility in the UK: Does size matter? A comparison between commercial and investment banks. Research in International Business and Finance, 38, 137-150.

[7] Nair, M. (2016). Caste as self-regulatory club: evidence from a private banking system in nineteenth century India. Journal of Institutional Economics, 12(3), 677-698.

[8] Wilson, K., \& Veuger, S. (2017). Information frictions in uncertain regulatory environments: Evidence from us commercial banks. Oxford Bulletin of Economics and Statistics, 79(2), 205-233.

[9] Stewart, C., Matousek, R., \& Nguyen, T. N. (2016). Efficiency in the Vietnamese banking system: A DEA double bootstrap approach. Research in International Business and Finance, 36, 96-111. 